\title{
Expected Onset of Rad/Nuc Targeted Injury
}

National Cancer Institute

\section{Source}

National Cancer Institute. Expected Onset of Rad/NuC Targeted Injury. NCI Thesaurus.

Code C161502.

A description as to the expected onset of the targeted effect produced by the challenge agent. 